\title{
Does surgical procedure type impact postoperative pain and recovery in deep inferior epigastric artery perforator flap breast reconstruction?
}

\author{
Alexander A. Azizi ${ }^{1}$, Anita T. Mohan ${ }^{1,2}$, Taj Tomouk ${ }^{1,3}$, Elizabeth B. Brickley ${ }^{4}$, Charles M. Malata ${ }^{1,5}$ \\ ${ }^{1}$ Department of Plastic and Reconstructive Surgery, Addenbrooke's Hospital, Cambridge University Hospitals NHS Foundation Trust, \\ Cambridge, UK; ${ }^{2}$ Division of Plastic Surgery, Mayo Clinic, Rochester, MN, USA; ${ }^{3}$ Department of Surgery, Royal Free London NHS \\ Foundation Trust, London; ${ }^{4}$ Department of Infectious Disease Epidemiology, London School of Hygiene \& Tropical Medicine, London; \\ ${ }^{5}$ School of Medicine, Anglia Ruskin University, Chelmsford, UK
}

Background The deep inferior epigastric artery perforator (DIEP) flap is the commonest flap used for breast reconstruction after mastectomy. It is performed as a unilateral (based on one [unipedicled] or two [bipedicled] vascular pedicles) or bilateral procedure following unilateral or bilateral mastectomies. No previous studies have comprehensively analyzed analgesia requirements and hospital stay of these three forms of surgical reconstruction.

Methods A 7-year retrospective cohort study (2008-2015) of a single-surgeon's DIEP-patients was conducted. Patient-reported pain scores, patient-controlled morphine requirements and recovery times were compared using non-parametric statistics and multivariable regression.

Results The study included 135 participants: unilateral unipedicled $(n=84)$, unilateral bipedicled $(n=24)$ and bilateral unipedicled $(n=27)$. Univariate comparison of the three DIEP types showed a significant difference in 12-hour postoperative morphine requirements $(P=0.020)$; bipedicled unilateral patients used significantly less morphine than unipedicled (unilateral) patients at $12(P=0.005), 24(P=0.020)$, and $48(P=0.046)$ hours. Multivariable regression comparing these two groups revealed that both reconstruction type and smoking status were significant predictors for 12-hour postoperative morphine usage $(P=0.038$ and $P=0.049$, respectively), but only smoking, remained significant at $24(P=0.010)$ and $48(P=0.010)$ hours. Bilateral reconstruction patients' mean hospital stay was 2 days longer than either unilateral reconstruction $(\mathrm{P}<0.001)$.

Conclusions Although all three forms of DIEP flap breast reconstruction had similar postoperative pain measures, a novel finding of our study was that bipedicled DIEP flap harvest might be associated with lower early postoperative morphine requirements. Bilateral and bipedicled procedures in appropriate patients might therefore be undertaken without significantly increased pain/morbidity compared to unilateral unipedicled reconstructions.

Keywords Pain, postoperative / Perforator flap / Mammaplasty / Surgical flap / DIEP flap
Correspondence: Charles M. Malata Department of Plastic and Reconstructive Surgery, Addenbrooke's Hospital, Cambridge University Hospitals NHS Foundation Trust, Box 186, Hills Road, Cambridge, CB2 000, UK

Tel: +44-1223-586672

Fax: +44-1223-257177

E-mail:cmalata@hotmail.com
This study was presented at the $53 \mathrm{rd}$ Congress of the European Society for Surgical Research on May 30-June 2, 2018, in Madrid, Spain. 


\section{INTRODUCTION}

Post-mastectomy breast reconstruction can be undertaken using implants, the patient's own tissues or a combination. The advantages of using autologous tissue include superior cosmesis and avoidance of implant-related complications [1]. The commonest autologous donor site is the lower abdomen which yields ample amounts of well vascularized tissue which is often harvested as a perforator flap namely the deep inferior epigastric artery perforator (DIEP) [2,3]. Perforator flaps have reduced donor site morbidity and postoperative analgesic requirements with improved patient satisfaction compared to muscle-containing flaps such as the transverse rectus abdominis myocutaneous (TRAM) flaps [2]. DIEP flaps are hence considered the gold standard for autologous breast reconstruction [3]. DIEP flap breast reconstruction can be performed as a unilateral or bilateral procedure following unilateral or bilateral mastectomies. The unilateral flap can be harvested based on one (unipedicled) or two (bipedicled) vascular pedicles. The bipedicled flap entails vessel dissection through the substance and sheath of the rectus muscles on both sides of the lower abdomen akin to the harvest of two separate flaps (bilateral breast reconstruction) but is then used for the reconstruction of one rather two breasts (unilateral bipedicled category). Reduced postoperative pain is correlated with decreased complications, accelerated discharge from hospital, and improved patient experience [4]. There have hitherto been no detailed direct comparisons of early postoperative recovery based on solely DIEP flap procedure type.

The aim of the study therefore was to compare postoperative pain and early recovery for bilateral unipedicled, unilateral unipedicled and unilateral bipedicled DIEP flap breast reconstructions to determine if there was a difference in the early morbidity associated with these procedure subtypes. It was hypothesized that since bilateral procedures and bipedicled procedures are more invasive they could lead to increased pain, morbidity and hospital stay.

\section{METHODS}

A 7-year retrospective cohort study (2008-2015) of consecutive patients $(n=178)$ was conducted at a single tertiary referral center. All patients underwent post-mastectomy DIEP free flap breast reconstruction by one surgeon (CMM). They were identified from a prospectively collected free flap database and the surgeon's free flap logbook. This cohort was then divided into three groups based on type of DIEP breast reconstruction; all were anastomosed to the internal mammary vessels exposed via the total rib preservation technique. Patients were classified ac- cording to whether they had unilateral breast reconstruction with either a single vascular pedicle (unilateral unipedicled) or a double pedicle (unilateral bipedicled) or a bilateral breast reconstruction using hemi-DIEP flaps based on a single pedicle (bilateral unipedicled).

Data were extracted from the patient's electronic and paper medical records. Postoperative analgesia was provided using the senior author's standardized protocol: morphine-based intravenous (IV) patient-controlled analgesia (PCA) device, regular maximum dose IV paracetamol and supplemented (rarely and recorded) with oral morphine alone. The data collected included: the patient's age, weight, body mass index (BMI), the duration of PCA use, time to catheter removal (as a proxy for time to ambulation), length of hospital stay, total morphine use at 12, 24 and 48 hours postoperatively (both total and per kilogram body weight), self-reported pain scores sampled every 4 hours until the PCA was taken down, maximum pain scores and pain score on discharge. Pain scores were reported on the 11-point numerical rating scale (NRS). Additional oral morphine was converted to the equivalent dose in terms of the IV PCA (at a ratio of 2:1) [5].

This study was part of a quality improvement assessment and an ongoing departmental free flap audit within the university hospital. Quality improvement and audit assessments are part of a larger framework for clinical governance. Clinical governance is compulsory within the UK National Health Service (NHS), therefore no specific ethical committee approval was needed, and individual patient consent for their anonymized retrospective data was not required to conduct or publish this study.

Patients who underwent superficial inferior epigastric artery perforator $(n=6)$ or free TRAM $(n=1)$ flap harvest, did not have rib-preserving DIEP reconstructive surgery $(n=1)$, or had insufficient medical information $(n=35)$ were excluded from the study (Fig. 1).

Continuous and approximately normal data such as age, weight and BMI were compared across the three procedure types using an analysis of variance test. Discrete (categorical) data such as smoking status, diabetic comorbidity, incidence of nausea and vomiting, prior chemotherapy and prior radiotherapy were compared using chi-square tests. The postoperative pain scores, total morphine doses used, time to PCA discontinuation, postoperative catheter removal and length of hospital stay were nonnormal and compared non-parametrically across the three procedure types using Kruskal Wallis tests. Multivariable linear regression used the REG regression application on SAS (vide infra) supposing independent effects. Total morphine doses and total doses per kilogram across two procedure types were compared using Mann Whitney U tests. 


\section{Fig. 1. A flow diagram}

A flow diagram describing the patients included and excluded from the final study cohort. DIEP, deep inferior epigastric artery perforator.

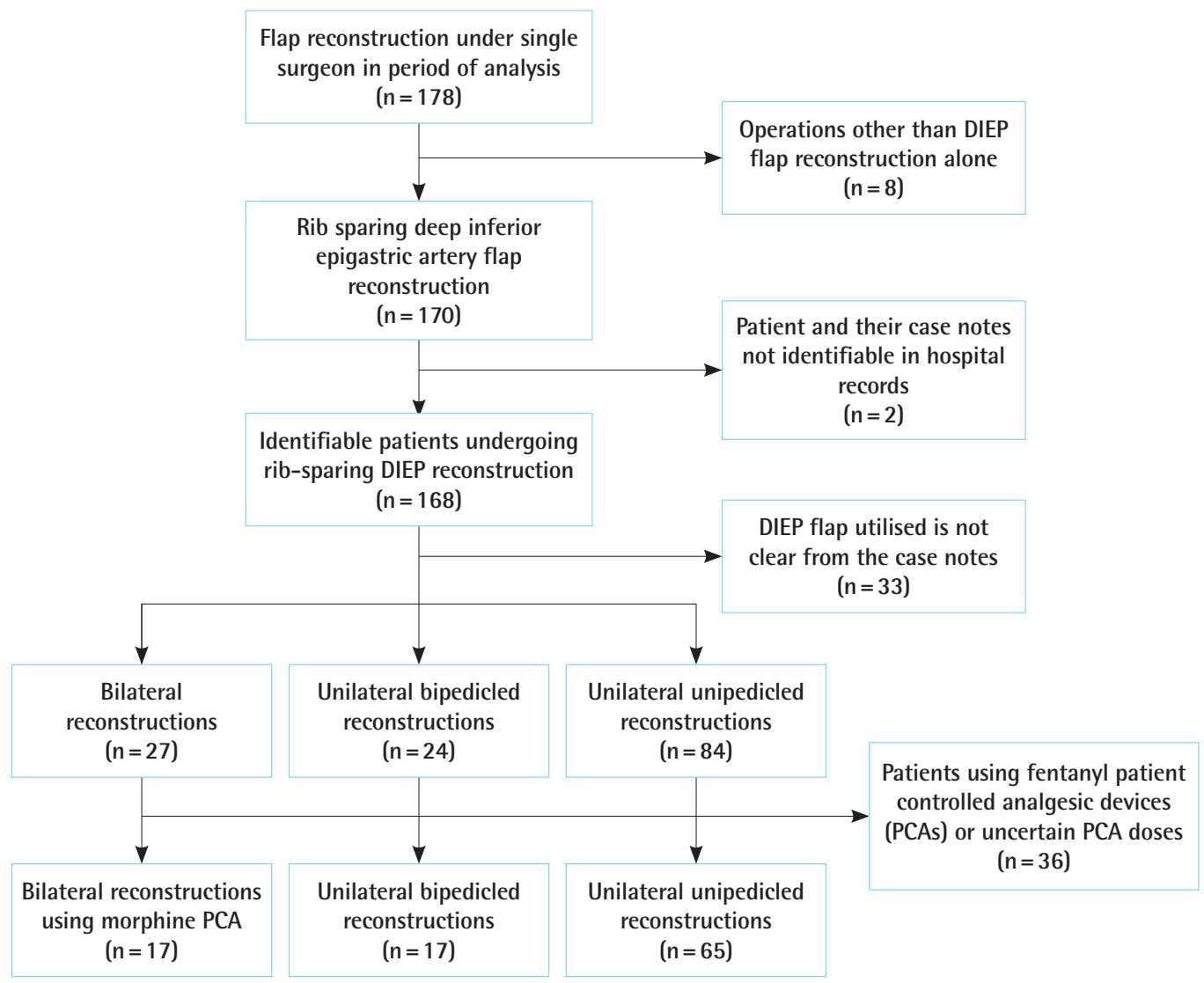

Any patients given fentanyl as the opioid in their PCA regimen or if their morphine doses were uncertain $(n=36)$ were excluded from the comparisons of morphine. Data were stored on an excel spreadsheet and all statistical analyses were conducted on specific statistical software: SAS (Statistical Analysis System) release 3.71, University Edition 2.7 9.4 M5 (“SAS”). All statistical tests were two-sided and $\alpha=0.05$ was deemed significant.

\section{RESULTS}

\section{Demographics}

The study sample ( $n=135$ patients) was categorized into three DIEP groups: unilateral unipedicled $(n=84)$, unilateral bipedicled $(n=24)$ and bilateral unipedicled $(n=27)$ reconstructions (referred to as unipedicled, bipedicled and bilateral reconstructions respectively). The mean age of the cohort was 47.3 years and it was significantly different across the three groups $(P=0.002)$. The bilateral group patients were younger $(42.9$ years) than those in the bipedicled ( 45 years) and unipedicled
(49.5 years) groups. Patients undergoing bipedicled flap reconstruction of a single breast were also significantly younger than those undergoing unipedicled surgery $(P=0.039)$. The mean BMI of the cohort was $28.5 \mathrm{~kg} / \mathrm{m}^{2}$ and it was significantly different across the three groups $(\mathrm{P}<0.001)$. The bipedicled group had a lower BMI $\left(24.7 \mathrm{~kg} / \mathrm{m}^{2}\right)$ compared to bilateral patients $\left(30.3 \mathrm{~kg} / \mathrm{m}^{2}\right)$ and unipedicled patients $\left(29.1 \mathrm{~kg} / \mathrm{m}^{2}\right)(\mathrm{Ta}-$ ble 1). The UK mean for women is $27.0 \mathrm{~kg} / \mathrm{m}^{2}$ [6].

\section{Morphine use: across all three groups}

The mean total morphine used by 12 hours postoperatively in the various procedure types was significantly different $(\mathrm{P}=$ 0.020, Kruskal Wallis test) being $17.2 \mathrm{mg}, 19.7 \mathrm{mg}$, and $8.9 \mathrm{mg}$ for the bilateral, unilateral unipedicled and unilateral bipedicled groups respectively (Table 2 ). There was, however, no statistical difference in total morphine use at 24 and 48 hours.

The total morphine dose at 12 hours postoperatively was then analyzed by multivariable linear regression including the variables of reconstruction type, patient age, BMI, reconstruction 


\begin{tabular}{|c|c|c|c|c|}
\hline Characteristic & $\begin{array}{l}\text { Bilateral } \\
\text { reconstruction } \\
(n=27)\end{array}$ & $\begin{array}{l}\text { Bipedicled, unilateral } \\
\text { reconstruction } \\
(n=24)\end{array}$ & $\begin{array}{l}\text { Unipedicled, unilateral } \\
\text { reconstruction } \\
(n=84)\end{array}$ & P-value ${ }^{a)}$ \\
\hline Age at operation (yr) & $42.9 \pm 8.7$ & $45.0 \pm 7.0$ & $49.5 \pm 9.4$ & $0.002^{b)}$ \\
\hline Weight (kg) & $85.3 \pm 13.1$ & $65.7 \pm 7.5$ & $77.5 \pm 12.2$ & $<0.001^{\mathrm{b})}$ \\
\hline $\mathrm{BMI}\left(\mathrm{kg} / \mathrm{m}^{2}\right)$ & $30.3 \pm 3.6$ & $24.7 \pm 3.7$ & $29.1 \pm 4.3$ & $<0.001^{\text {b) }}$ \\
\hline Timing of reconstruction & & & & $<0.001$ \\
\hline Combination & $6(22.2)$ & 0 & 0 & \\
\hline Delayed & 0 & 3 (12.5) & $21(25.0)$ & \\
\hline Immediate & $21(77.8)$ & $21(87.5)$ & $62(73.8)$ & \\
\hline Salvage & 0 & 0 & $1(1.2)$ & \\
\hline Smoking status & & & & 0.29 \\
\hline Non-smoker & 25 (92.6) & 23 (95.8) & $77(92.7)$ & \\
\hline Smoker & $1(3.7)$ & 0 & 7 (8.3) & \\
\hline Not available & $1(3.7)$ & $1(4.1)$ & 0 & \\
\hline Diabetic comorbidity & & & & 0.55 \\
\hline Non-diabetic & $26(96.3)$ & 23 (95.8) & $81(96.4)$ & \\
\hline Diabetic & 0 & 0 & $2(2.4)$ & \\
\hline Not available & $1(3.7)$ & $1(4.1)$ & $1(1.19)$ & \\
\hline Chemotherapy & & & & 0.71 \\
\hline No chemotherapy & 6 (22.2) & $4(16.7)$ & $20(23.8)$ & \\
\hline Experienced chemotherapy & $21(77.8)$ & 20 (83.3) & $61(72.6)$ & \\
\hline Not available & 0 & 0 & $3(3.6)$ & \\
\hline Radiotherapy & & & & 0.8 \\
\hline No radiotherapy & 9 (33.3) & 8 (33.3) & $31(36.9)$ & \\
\hline Experienced radiotherapy & $18(66.7)$ & 15 (62.5) & 47 (55.9) & \\
\hline Not available & 0 & $1(4.1)$ & $6(7.1)$ & \\
\hline
\end{tabular}

timing, smoking status, diabetic disease, prior chemotherapy and radiotherapy. The regression analysis showed that of these, only procedure type was associated with a statistically significant difference in morphine requirements $(\mathrm{P}=0.036)$.

\section{Morphine use: pairwise comparisons}

The previous section described that there was a difference in morphine use at the 12-hour timepoint across all three groups and, although the mean total use at the 12-hour time point was most different between unipedicled $(19.7 \mathrm{mg}$ ) and bipedicled (8.9 mg) unilateral groups, it did not reveal that the difference between the three was due to a significant difference between any two particular groups. To find out why there was a significant difference between the three operative groups, pairwise comparisons (i.e., unilateral bipedicled vs. unilateral unipedicled, unilateral bipedicled vs. bilateral, unilateral unipedicled vs. bilateral) of the postoperative morphine requirements at 12, 24, and 48 hours were performed (Mann Whitney U tests). The only statistically significant differences were found when comparing the unilateral unipedicled and unilateral bipedicled re- constructions, and not just at the 12-hour time point which is what was seen in the comparison across the three groups. Patients undergoing bipedicled reconstructions consistently required a significantly lower total morphine dose than unipedicled reconstructions at 12,24 , and 48 hours postoperatively (Table 3). After 12 hours, the total morphine requirements for bipedicled and unipedicled reconstructions were $8.9 \mathrm{mg}$ and $19.7 \mathrm{mg}$ respectively $(\mathrm{P}=0.005)$, after 24 hours were $18.8 \mathrm{mg}$ and $35.5 \mathrm{mg}$ respectively $(\mathrm{P}=0.020)$, and after 48 hours were $30.3 \mathrm{mg}$ and $53.2 \mathrm{mg}$ respectively $(\mathrm{P}=0.046)$. These differences are clinically significant as the morphine use in bipedicled DIEPs was almost half than required by patients undergoing unilateral unipedicled procedures.

\section{Morphine use: multivariable analysis on the unipedicled and bipedicled comparison}

A multivariable linear regression was performed to compare the bipedicled and unipedicled total morphine requirements at the 12-, 24-, and 48-hour timepoints postoperatively (Table 4). This showed that the total morphine doses at 12 hours postop- 
Table 2. Twenty-five postoperative outcomes which were described and compared statistically across the three types of DIEP flap breast reconstruction $(n=135)$

\begin{tabular}{|c|c|c|c|c|}
\hline Characteristic & $\begin{array}{l}\text { Bilateral } \\
\text { reconstruction } \\
(n=27)\end{array}$ & $\begin{array}{l}\text { Bipedicled, unilateral } \\
\text { reconstruction } \\
(n=24)\end{array}$ & $\begin{array}{l}\text { Unipedicled, unilateral } \\
\text { reconstruction } \\
(\mathrm{n}=84)\end{array}$ & P-value ${ }^{a)}$ \\
\hline Time after surgery when PCA discontinued (hr) & $50.8(42.1-59.5)$ & $50.5(39.1-61.9)$ & $49.8(45.3-54.3)$ & 0.93 \\
\hline Postoperative catheter removal (hr) & $85.3(75.9-94.8)$ & $95.8(76.3-115.2)$ & $83.1(78.6-87.6)$ & 0.26 \\
\hline Length of hospital stay (day) & $10.2(9.1-11.3)$ & $7.8(7-8.5)$ & $7.7(7.2-8.3)$ & $<0.001$ \\
\hline \multicolumn{5}{|l|}{ Total morphine use } \\
\hline After $12 \mathrm{hr}(\mathrm{mg})$ & $17.2(10.1-24.2)$ & $8.9(4.9-13.0)$ & $19.7(15.7-23.6)$ & 0.02 \\
\hline After 12 hr per kg (mg/kg) & $0.20(0.13-0.29)$ & $0.15(0.08-0.21)$ & $0.25(0.20-0.30)$ & 0.11 \\
\hline After $24 \mathrm{hr}(\mathrm{mg})$ & $29.7(19.0-40.3)$ & $18.8(10.2-27.4)$ & $35.5(28.4-42.6)$ & 0.06 \\
\hline After 24 hr per kg (mg/kg) & $0.38(0.26-0.50)$ & $0.29(0.15-0.42)$ & $0.45(0.36-0.53)$ & 0.18 \\
\hline After $48 \mathrm{hr}(\mathrm{mg})$ & $41.1(25.0-57.1)$ & $30.3(14.9-45.6)$ & $53.2(41.6-64.9)$ & 0.13 \\
\hline After 48 hr per kg (mg/kg) & $0.40(0.20-0.70)$ & $0.47(0.22-0.72)$ & $0.70(0.54-0.83)$ & 0.25 \\
\hline \multicolumn{5}{|l|}{ Pain score } \\
\hline At $0 \mathrm{hr}$ & $1.3(0.2-2.5)$ & $1.7(0.6-2.7)$ & $2.5(1.7-3.2)$ & 0.24 \\
\hline At $4 \mathrm{hr}$ & $1.2(0.6-1.8)$ & $1.3(0.6-2)$ & $1.5(1.2-1.9)$ & 0.65 \\
\hline At $8 \mathrm{hr}$ & $1.8(0.6-3.0)$ & $0.9(0.4-1.4)$ & $1.2(0.9-1.5)$ & 0.2 \\
\hline At $12 \mathrm{hr}$ & $2.4(1.5-3.3)$ & $2.1(1-3.1)$ & $2(1.5-2.4)$ & 0.72 \\
\hline At $16 \mathrm{hr}$ & $1.4(0.4-2.3)$ & $1.9(0.8-3)$ & $1.6(1.2-2)$ & 0.72 \\
\hline At $20 \mathrm{hr}$ & $1.7(0.5-2.9)$ & $2.1(1.2-3.1)$ & $2(1.6-2.4)$ & 0.8 \\
\hline At $24 \mathrm{hr}$ & $1.3(0.5-2.0)$ & $2.3(1-3.7)$ & $1.8(1.3-2.2)$ & 0.28 \\
\hline At $28 \mathrm{hr}$ & $1.4(0.6-2.2)$ & $1.7(1-2.4)$ & $1.7(1.2-2.1)$ & 0.83 \\
\hline At $32 \mathrm{hr}$ & $1.7(0.9-2.5)$ & $1.4(0.6-2.1)$ & $1.8(1.3-2.3)$ & 0.65 \\
\hline At $36 \mathrm{hr}$ & $1.3(0.2-2.4)$ & $1.0(0-2.0)$ & $1.6(1.1-2.1)$ & 0.57 \\
\hline At $40 \mathrm{hr}$ & $2.0(0.5-3.5)$ & $2(0.8-3.2)$ & $1.7(1.1-2.3)$ & 0.87 \\
\hline At $44 \mathrm{hr}$ & $1.9(0.8-3.0)$ & $2.7(1.3-4.0)$ & $1.6(1.1-2.1)$ & 0.16 \\
\hline At $48 \mathrm{hr}$ & $1.1(-0.1-2.3)$ & $1.5(-0.1-3.1)$ & $1.2(0.7-1.6)$ & 0.85 \\
\hline Pain score at discharge & $1.1(0.3-1.8)$ & $1.3(0.3-2.3)$ & $0.7(0.4-1.0)$ & 0.27 \\
\hline Maximum pain score & $5.9(4.7-7.0)$ & $4.5(3.5-5.6)$ & $5.2(4.7-5.7)$ & 0.2 \\
\hline $\begin{array}{l}\text { Time postoperative when maximum pain score } \\
\text { experienced (hr) }\end{array}$ & $14.9(9.5-20.2)$ & $14.3(7.9-20.6)$ & $13.4(10.7-16.0)$ & 0.88 \\
\hline
\end{tabular}

\section{Table 3. Comparing patients' total morphine requirements within the first 48 hours postoperatively: unilateral bipedicled} compared to unilateral unipedicled DIEP reconstructions

\begin{tabular}{|c|c|c|c|}
\hline Total morphine use & $\begin{array}{l}\text { Bipedicled, unilateral reconstruction } \\
\qquad(n=17)\end{array}$ & $\begin{array}{l}\text { Unipedicled, unilateral reconstruction } \\
\qquad(n=65)\end{array}$ & P-value \\
\hline After 12 hr (mg) & $6.8(3.0-18.0)$ & $17.5(7.8-26.5)$ & 0.005 \\
\hline After $12 \mathrm{hr}$ per $\mathrm{kg}(\mathrm{mg} / \mathrm{kg})$ & $0.11(0.06-0.28)$ & $0.23(0.11-0.36)$ & 0.040 \\
\hline After $24 \mathrm{hr}(\mathrm{mg})$ & $11.0(4.0-30.0)$ & $29.0(12.8-50.0)$ & 0.020 \\
\hline After 24 hr per kg (mg/kg) & $0.17(0.06-0.50)$ & $0.40(0.18-0.61)$ & 0.064 \\
\hline After $48 \mathrm{hr}(\mathrm{mg})$ & $14.0(4.0-49.3)$ & $43.8(18.8-77.0)$ & 0.046 \\
\hline After $48 \mathrm{hr}$ per $\mathrm{kg}(\mathrm{mg} / \mathrm{kg})$ & $0.22(0.06-0.80)$ & $0.51(0.24-0.96)$ & 0.110 \\
\hline
\end{tabular}

eratively were still significantly lower for bipedicled reconstructions than unipedicled $(\mathrm{P}=0.038)$. Additionally, non-smokers used significantly less morphine $(\mathrm{P}=0.049)$ than smokers. However, at 24 hours, being a non-smoker was the only significantly different variable $(\mathrm{P}=0.01)$; the procedure type was no longer significant $(\mathrm{P}=0.11)$. At 48 hours, additional factors were significant for reduced morphine usage: being a nonsmoker $(P=0.01)$, younger $(P=0.013)$ and a recipient of neoadjuvant chemotherapy $(\mathrm{P}=0.03)$. As at 24 hours the type of reconstruction was no longer a significant factor $(\mathrm{P}=0.18)$. 
Table 4. Regression model of total morphine use for patients undergoing unilateral bipedicled $(n=17)$ and unilateral unipedicled $(n=65)$ DIEP reconstructions at different timepoints

\begin{tabular}{|c|c|c|c|c|c|c|c|}
\hline \multirow[t]{2}{*}{ Parameter } & & \multicolumn{2}{|c|}{$\begin{array}{l}\text { Total morphine use after } \\
12 \mathrm{hr}(\mathrm{mg})\end{array}$} & \multicolumn{2}{|c|}{$\begin{array}{l}\text { Total morphine use after } \\
24 \mathrm{hr}(\mathrm{mg})\end{array}$} & \multicolumn{2}{|c|}{$\begin{array}{l}\text { Total morphine use after } \\
48 \mathrm{hr}(\mathrm{mg})\end{array}$} \\
\hline & & Co-efficient & P-value & Co-efficient & P-value & Co-efficient & P-value \\
\hline \multicolumn{2}{|l|}{ Age at operation (yr) } & -0.18 & 0.34 & 0.51 & 0.086 & -1.16 & 0.013 \\
\hline \multicolumn{2}{|c|}{ Body mass index $\left(\mathrm{kg} / \mathrm{m}^{2}\right)$} & 0.02 & 0.95 & 0.12 & 0.84 & -0.27 & 0.76 \\
\hline \multirow[t]{2}{*}{ Timing of reconstruction } & Delayed ${ }^{\mathrm{a})}$ & -4.03 & 0.33 & -10.10 & 0.12 & -12.40 & 0.23 \\
\hline & Immediate & Reference & & Reference & & Reference & \\
\hline \multirow[t]{2}{*}{ Smoking status } & Non-smoker ${ }^{\text {a) }}$ & -12.10 & 0.049 & -25.70 & 0.010 & -38.47 & 0.01 \\
\hline & Smoker & Reference & & Reference & & Reference & \\
\hline \multirow[t]{2}{*}{ Diabetic comorbidity } & Non-diabetic ${ }^{\text {a) }}$ & 13.90 & 0.16 & 16.10 & 0.31 & 14.60 & 0.55 \\
\hline & Diabetic & Reference & & Reference & & Reference & \\
\hline \multirow[t]{2}{*}{ Chemotherapy } & No chemotherapy ${ }^{a)}$ & 4.61 & 0.34 & 13.90 & 0.07 & 25.50 & 0.03 \\
\hline & Experienced chemotherapy & Reference & & Reference & & Reference & \\
\hline \multirow[t]{2}{*}{ Radiotherapy } & No radiotherapya) & -5.13 & 0.21 & -7.20 & 0.26 & -5.39 & 0.59 \\
\hline & Experienced radiotherapy & Reference & & Reference & & Reference & \\
\hline \multirow[t]{2}{*}{ Type of reconstruction } & Bipedicledal $^{\text {a) }}$ & -8.73 & 0.038 & -10.50 & 0.11 & -13.90 & 0.18 \\
\hline & Unipedicled & Reference & & Reference & & Reference & \\
\hline
\end{tabular}

\section{Pain scores: across all three groups then pairwise}

Three-way comparison: there were no statistical differences (Kruskal Wallis tests) in patient pain scores between the three types of reconstruction at 4 hourly intervals in the first 48 -hour postoperative period, including at 0 hour (i.e., immediately postoperatively when the mean pain scores were $1.3,1.7$, and 2.5 for bilateral, unilateral bipedicled and unilateral unipedicled patients respectively). Similarly, there were no significant differences between the three procedure types for pain scores on discharge, nor between their maximum postoperative pain scores, time of maximum pain scores or the length of PCA use (Table 2).

Pairwise comparisons: there were no statistically significant differences in 4-hourly pain scores in the first 48 hours between unilateral and bilateral reconstructions or between bipedicled and bilateral reconstructions when compared directly (Mann Whitney U test).

\section{Maximal pain scores}

$84 \%$ of patients reported their maximum pain scores in the first 24 hours post-surgery and there was no difference in the maximum pain scores experienced dependent upon the three procedure types ( $\mathrm{P}=0.24$, Kruskal Wallis test) (Table 2).

\section{Other parameters}

A high proportion of patients (61.0\%) experienced postoperative nausea or vomiting. There was no significant difference in proportions of those experiencing nausea and vomiting based on procedure type $(\mathrm{P}=0.97$; chi-square statistical test $)$. Fur- thermore, there seemed to be no relationship between the total morphine usage and whether the patient suffered from troublesome nausea and vomiting or not at the 12,24 or 48-hour timepoints $(\mathrm{P}=0.93, \mathrm{P}=0.69, \mathrm{P}=0.88$, respectively; Mann Whitney U statistical test).

Time to catheter removal, a proxy for ambulation post-procedure, was not significantly different between the three groups ( $P=0.26$, Kruskal Wallis statistical test). However, mean length of hospital stay in the bilateral group was significantly longer at 10.2 days compared to unilateral reconstructions (bipedicled $=7.8$ days, $\mathrm{P}<0.001$; unipedicled $=7.7$ days, $\mathrm{P}<0.001$; Mann Whitney U statistical test).

\section{DISCUSSION}

This is the first study to examine a comprehensive set of measures of postoperative pain in DIEP reconstructions exclusively and to include a detailed analysis of the pain profile of the unilateral bipedicled DIEP flap breast reconstructions [7-9]. Such data would be useful for patient counselling and serve to better inform us on optimising pain control. This also provides vital information to develop enhanced recovery programs with the goal to improve patient experience. In order to eliminate interoperator variability and the effect on pain perception caused by different flap recipient vessel sites, all the patients were operated on using a standardized, rib-sparing technique of internal mammary recipient vessel exposure, with a standardized postoperative protocol and by a single experienced microsurgeon. 
The published literature suggests that bilateral free flap breast reconstructions might lead to greater postoperative pain than unilateral procedures [7-9]. For example, in Gassman et al. series $(\mathrm{n}=834)$, patients undergoing bilateral breast reconstruction with several different types of abdominal based autologous flaps had significantly greater early postoperative morphine requirements and pain scores than unilateral reconstructions [8]. Similarly, Kulkarni et al. $(\mathrm{n}=2,207)$ documented increased patient-reported measures of early postoperative pain for different forms of bilateral reconstructive breast surgery [7]. This is not surprising as bilateral flap harvest is more invasive and such surgery involves operating on two breasts. There is little published data on postoperative pain and early recovery specifically for different forms of DIEP flap reconstruction and there is only one previous study comparing postoperative pain and the number of vascular pedicles in DIEP reconstruction; Uda et al. $(n=67)$ report a single, patient-reported global measure of postoperative pain immediately after surgery and found that patients with bipedicled DIEP flap reconstruction had significantly more life-limiting pain than unipedicled patients [9]. This is in direct contrast to our findings that this cohort of patients experienced less pain and required less morphine postoperatively.

In the present study, bipedicled reconstructions led to the use of significantly lower doses of total morphine after 12 hours postoperatively across the three procedure types after both univariate and multivariable analyses. In addition, bipedicled reconstructions required significantly lower doses of total morphine when compared to unilateral unipedicled reconstructions after 12,24 , and 48 hours postoperatively using univariate analyses. Multivariable linear regression confirmed that bipedicled reconstruction was still associated with lower postoperative morphine requirements at 12 hours. This remains an unexpected finding and is contrary to our expectations and the findings of others [9]. We would have anticipated that bipedicled unilateral reconstruction patients should have more pain and higher morphine use due to two donor sites and often exposure of two intercostal spaces for the microanastomoses to the internal mammary vessels. Additionally, these were slightly younger patients and the literature suggests that they may tend towards higher morphine use $[7,10]$. More work needs to be done in this regard possibly also examining intraoperative depth of sedation and analgesia to help to decipher this conundrum.

Although, at 24 hours the difference observed on univariate analysis between bipedicled and unipedicled reconstructions was shown on multivariable analysis to be attributed to smoking status and at 48 hours to smoking status, younger age and prior chemotherapy. No other differences between patients undergoing bipedicled unilateral, unipedicled unilateral and bilateral re- constructions were observed in 21 other parameters (Table 2). Multivariable regression analysis highlighted that smoking, age and prior chemotherapy affect postoperative morphine requirements. Being a non-smoker reduced postoperative morphine requirements after 12,24 , and 48 hours when comparing the unipedicled and bipedicled patients in our cohort. Additionally, at 48 hours increasing age and prior chemotherapy significantly decreased morphine requirements. Being a smoker is a well described cause of increased postoperative morphine use and this is likely due to nicotine's chronic effects on the nicotinic acetylcholine receptor [11]. However, in our study this finding should be interpreted with caution due to the small patient numbers. Older age has been associated with lower postoperative morphine requirements in various types of surgery [10]. In addition, younger age leading to higher pain scores have been observed in breast surgery, but not yet for morphine requirements [7]. Another novel finding from our study was that prior chemotherapy has not hitherto been reported to be associated with differences in postoperative morphine requirements or pain scores.

Our cohort's total morphine requirements (mean \pm standard deviation) were $31.6 \pm 26.3 \mathrm{mg}$ at 24 hours and $47.2 \pm 43 \mathrm{mg}$ at 48 hours, which is comparable to or lower than similar datasets $[12,13]$. Zhong et al. [13] reported a 44 patient case series of predominately DIEP (68\%) flap autologous breast reconstructions in which the total equivalent morphine use was 30.0 \pm 19.1 $\mathrm{mg}$ at 24 hours. This suggests that our figures are valid and the results likely to be applicable to similar patients in other centers.

As regards patient-reported pain scores, there is one comparable data set. Parikh et al. [14] in a case series of 78 microvascular free flap transfers of abdominal autologous tissue report median (interquartile range, IQR) pain scores at 2 hours of 5 (IQR, 4-6) on the 11-point NRS and 4 (IQR, 3-5) at 24 hours; our whole cohort has median pain scores of 1 (IQR, $0-4$ ) at 0 hour, 1 (IQR, $0-2)$ at 4 hours and 1 (IQR, $0-3$ ) at 24 hour on a 10 point NRS. This suggests that pain in our cohort was well controlled compared to published literature.

It was interesting that patients who did and did not experience postoperative nausea and vomiting did not use significantly different amounts of morphine postoperatively at the 12-, 24-, and 48-hour time points; this makes it unlikely that morphine is the predominant factor causing nausea and vomiting.

Bilateral reconstructions had statistically and clinically significantly longer lengths of stay by 2.4 days (Table 2). This increase for bilateral procedures is well documented in the literature [15]. It is also expected as bilateral surgery is more invasive, lasts longer and is associated with a longer recovery in terms of mobilization. However, our study suggests that this is not due to increased pain at the donor sites or the need for greater morphine. 
Our length of stay is however similar to representative UK cohorts of DIEP and other autologous tissue-based breast reconstructions which have reported mean length of stay ranging between 6.8 and 10.2 days [16-18]. Historically earlier discharges have been reported in North American studies with mean length of stay between 4 and 5 days $[14,15,19,20]$.

Several limitations of this study are due to the retrospective study design. Firstly, it is important to stress that this study contained relatively few participants and sample size which included small numbers in key categories such as different times of reconstruction, diabetic patients and smokers. For example, there was ultimately only one patient in the bilateral group who smoked therefore the association with higher postoperative pain scores could have due to this single individual's unusual requirements rather than a robust phenomenon. It would have been informative to record a more complete evaluation of pain including the background, mobilization and breakthrough elements, whether the PCA was effective for reducing their pain, the systemic doses of intraoperative analgesics given and whether the patient took analgesics prior to admission because this could affect their baseline analgesic requirements [7]. Finally, a more robust evaluation of nausea and vomiting would have been informative; we could find out with a careful prospective study when the nausea and vomiting occurred and if that was related to recent morphine dosing.

The development and adoption of enhanced recovery pathways is a new and expanding area [21]. In breast reconstruction, these evidence-based pathways could help to improve postoperative morbidity, accelerate ambulation and perhaps discharge [21]. DIEP autologous flap breast reconstructions are associated with long operative and anaesthesia times, notable pain and morbidity [4]. Our study provides a baseline for us to quantify changes in opiate use and nausea and vomiting, for example if trialing regional blocks at the abdominal donor site, and in mobilization and discharge after intraoperative surgical site anaesthesia, early urinary catheter removal and earlier mobilization [14,20-22]. In addition, this study highlights that it might be more difficult to control the pain of patients who have received unipedicled reconstructions, are smokers, younger and have not received prior neoadjuvant chemotherapy. Incorporating these observations into official enhanced recovery pathways or enhancing current postoperative protocols could improve patient experience, their recovery and morbidity [21]. Therefore, since this study, in collaboration with our anesthetic colleagues we have developed an enhanced recovery after surgery protocol in which our anesthetists routinely administer gabapentin alongside PCA morphine to reduce morphine use, potentially nausea and vomiting and enable early ambulation.
In conclusions, this is the first study to demonstrate that bipedicled DIEP flap harvest might reduce early postoperative morphine requirements versus unipedicled procedures (whether patients are undergoing unilateral or bilateral breast reconstructions). Interestingly however, across numerous parameters, in our study sample, all three forms of DIEP flap breast reconstruction had similar measures of postoperative pain. Bilateral and bipedicled procedures in appropriate patients might therefore be undertaken without significantly increased pain/morbidity compared to unilateral unipedicled reconstructions. Bilateral free DIEP reconstruction, however, increase hospital stay and patients should be counselled appropriately.

\section{NOTES}

\section{Conflict of interest}

No potential conflict of interest relevant to this article was reported.

\section{Ethical approval}

This study was part of a quality improvement assessment and an ongoing departmental free flap audit within the university hospital. Quality improvement and audit assessments are part of a larger framework for clinical governance. Clinical governance is compulsory within the NHS, therefore no specific ethical committee approval was needed, and individual patient consent for their anonymized retrospective data was not required to conduct or publish this study.

\section{Author contribution}

Conception and design: AA Azizi, AT Mohan, T Tomouk, EB Brickley, CM Malata. Administrative support: AT Mohan, T Tomouk. Provision of study materials or patients: AT Mohan, CM Malata. Collection and assembly of data: AA Azizi, AT Mohan, T Tomouk, EB Brickley, CM Malata. Data analysis and interpretation: AA Azizi, AT Mohan, EB Brickley, CM Malata. Manuscript writing: all authors. Final approval: all authors.

\section{ORCID}

Alexander A. Azizi https://orcid.org/0000-0002-5216-1047 Anita T. Mohan https://orcid.org/0000-0001-9131-1047 Taj Tomouk https://orcid.org/0000-0003-1230-5090 Elizabeth B. Brickley https://orcid.org/0000-0003-0280-2288 Charles M. Malata https://orcid.org/0000-0002-0070-0838

\section{REFERENCES}

1. Patel NG, Ramakrishnan V. Microsurgical tissue transfer in 
breast reconstruction. Clin Plast Surg 2017;44:345-59.

2. Butler PD, Wu LC. Abdominal perforator vs. muscle sparing flaps for breast reconstruction. Gland Surg 2015;4:212-21.

3. Schmauss D, Machens HG, Harder Y. Breast reconstruction after mastectomy. Front Surg 2016;2:71.

4. Kroll SS, Sharma S, Koutz C, et al. Postoperative morphine requirements of free TRAM and DIEP flaps. Plast Reconstr Surg 2001;107:338-41.

5. Twycross RG, Wilcock A, Howard P. Palliative care formulary (PCF6). 6th ed. Nottingham: Palliativedrugs.com Ltd; 2017.

6. NCD Risk Factor Collaboration (NCD-RisC). Trends in adult body-mass index in 200 countries from 1975 to 2014: a pooled analysis of 1698 population-based measurement studies with 19.2 million participants. Lancet 2016;387:1377-96.

7. Kulkarni AR, Pusic AL, Hamill JB, et al. Factors associated with acute postoperative pain following breast reconstruction. JPRAS Open 2017;11:1-13.

8. Gassman AA, Yoon AP, Maxhimer JB, et al. Comparison of postoperative pain control in autologous abdominal free flap versus implant-based breast reconstructions. Plast Reconstr Surg 2015; 135:356-67.

9. Uda H, Tomioka YK, Sarukawa S, et al. Abdominal morbidity after single- versus double-pedicled deep inferior epigastric perforator flap use. J Plast Reconstr Aesthet Surg 2016; 69:1178-83.

10. Macintyre PE, Jarvis DA. Age is the best predictor of postoperative morphine requirements. Pain 1996;64:357-64.

11. Shi Y, Weingarten TN, Mantilla CB, et al. Smoking and pain: pathophysiology and clinical implications. Anesthesiology 2010;113:977-92.

12. Bar-Meir ED, Yueh JH, Hess PE, et al. Postoperative pain management in DIEP flap breast reconstruction: identification of patients with poor pain control. Eplasty 2010;10:e59.

13. Zhong T, Ojha M, Bagher S, et al. Transversus abdominis plane block reduces morphine consumption in the early postoperative period following microsurgical abdominal tissue breast reconstruction: a double-blind, placebo-controlled, randomized trial. Plast Reconstr Surg 2014;134:870-8.

14. Parikh RP, Sharma K, Guffey R, et al. Preoperative paravertebral block improves postoperative pain control and reduces hospital length of stay in patients undergoing autologous breast reconstruction after mastectomy for breast cancer. Ann Surg Oncol 2016;23:4262-9.

15. Frey JD, Salibian AA, Karp NS, et al. Examining length of hospital stay after microsurgical breast reconstruction: evaluation in a case-control study. Plast Reconstr Surg Glob Open 2017;5:e1588.

16. Mani M, Saour S, Ramsey K, et al. Bilateral breast reconstruction with deep inferior epigastric perforator flaps in slim patients. Microsurgery 2018;38:143-50.

17. Atherton DD, Hills AJ, Moradi P, et al. The economic viability of breast reconstruction in the UK: comparison of a single surgeon's experience of implant; LD; TRAM and DIEP based reconstructions in 274 patients. J Plast Reconstr Aesthet Surg 2011;64:710-5.

18. McAllister P, Teo I, Chin K, et al. Bilateral breast reconstruction with abdominal free flaps: a single centre, single surgeon retrospective review of 55 consecutive patients. Plast Surg Int 2016;2016:6085624.

19. Venkat R, Lee JC, Rad AN, et al. Bilateral autologous breast reconstruction with deep inferior epigastric artery perforator flaps: review of a single surgeon's early experience. Microsurgery 2012;32:275-80.

20. Batdorf NJ, Lemaine V, Lovely JK, et al. Enhanced recovery after surgery in microvascular breast reconstruction. J Plast Reconstr Aesthet Surg 2015;68:395-402.

21. Temple-Oberle C, Shea-Budgell MA, Tan M, et al. Consensus review of optimal perioperative care in breast reconstruction: Enhanced Recovery after Surgery (ERAS) society recommendations. Plast Reconstr Surg 2017;139:1056e-1071e.

22. Giordano S, Verajankorva E, Koskivuo I, et al. Effectiveness of local anaesthetic pain catheters for abdominal donor site analgesia in patients undergoing free lower abdominal flap breast reconstruction: a meta-analysis of comparative studies. J Plast Surg Hand Surg 2013;47:428-33. 